\title{
BMJ Global Health The world must prepare now for the next pandemic
}

\author{
Thomas R Frieden (1) , Marine Buissonnière, Amanda McClelland
}

To cite: Frieden TR, Buissonnière $\mathrm{M}$, McClelland $\mathrm{A}$ The world must prepare now for the next pandemic. BMJ Global Health

2021;6:e005184. doi:10.1136/ bmjgh-2021-005184

Handling editor Seye Abimbola

Received 28 January 2021 Accepted 30 January 2021
Check for updates

(c) Author(s) (or their employer(s)) 2021. Re-use permitted under CC BY-NC. No commercial re-use. See rights and permissions. Published by BMJ.

Resolve to Save Lives, New York, New York, USA

Correspondence to Dr Thomas R Frieden; tfrieden@rtsl.org

\section{INTRODUCTION}

The COVID-19 pandemic killed 2 million people worldwide in 2020 and cost an estimated US $\$ 20$ trillion $^{1}$; the world failed this test of preparedness and response. ${ }^{2}$ It remains to be determined whether the world will do better next time-because it is inevitable that there will be a next time. Unless countries act now to establish a route to readiness, the world will miss this opportunity to greatly reduce future health risks. Progress will require not only more and sustained leadership and funding from governments but also better technical capacity and improved operational excellence in public health systems across the globe. Strengthening our global health architecture will require country commitment and effective governance, effective use of increased financing, robust technical support, and the support of strong and accountable global leadership.

\section{FUNDING AND GOVERNANCE}

Closing gaps in epidemic preparedness in low-income and middle-income countries alone will cost at least US $\$ 5-\mathrm{US} \$ 10$ billion $^{3}$ and possibly as much as US\$35-US\$40 billion per year for the next decade. ${ }^{4}$ Funds are needed not only to build public health laboratories, emergency response capacities and train staff-one time or episodic costs that traditionally have been the primary areas development banks and bilateral donors have funded-but also for ongoing staff salaries, supplies, equipment maintenance and other recurring costs needed to find and stop both everyday and extraordinary threats. A crucial lesson from preparedness work over the past 20 years has been that the most effective emergency response systems build on robust, scalable systems that respond to everyday events. ${ }^{5}$

These funds are in addition to financing needed to strengthen research and development, which is being addressed, in part, through groups such as the Coalition for

\section{Summary box}

The world failed its test of preparedness and response to the COVID-19 pandemic, and it remains to be determined whether we will do better next time-because it is inevitable that there will be a next time.

- Progress will require not only more and sustained funding from governments but also better technical capacity and improved operational excellence in public health systems across the globe.

Strengthening our global health architecture will require country commitment and effective governance, effective use of financing and other resources, strong and accountable global leadership, robust technical support, substantial new funding with efficient financial mechanisms, and rigorous accountability.

- Success will also require a stronger commitment to collaboration and new ways of working together that recognise the reality - so vividly illustrated by the COVID-19 pandemic - of our mutual dependency and of the need for mutual accountability.

Epidemic Preparedness and Innovation and the Foundation for Innovative New Diagnostics, which also require additional, sustained resources. And the improvements go beyond changes needed to further strengthen WHO, which is pivotally important for a more effective global response. Despite substantial increases in global and bilateral funding for programmes in HIV, tuberculosis control and malaria through the Global Fund, the U.S. President's Emergency Plan for AIDS Relief, Unitaid and other organisations, and in immunisation through Gavi, the Vaccine Alliance and other groups, the capacity for detection, rapid response and prevention in most countries of the world-core public health capabilities-is far from what it needs to be.

More effective primary care systems are also of central importance in order to rapidly detect outbreaks, prevent infections of healthcare workers and provide the treatment and vaccines needed to save lives and stop the spread of infection. To support lower-income 
countries, financing that initially provides all or nearly all funds needed and then decreases the proportion of external assistance as countries increase domestic spending on these programs, potentially over a time frame as long as 10-20 years as domestic funding is scaled up, could increase funding stability. In addition, investments that support HIV, tuberculosis, malaria and vaccination programmes must be more effectively devoted to broad-based laboratory networks, disease tracking, epidemiology, rapid response and public health capacity platforms that address multiple infectious disease threats as well as to strengthening focused, accountable, patientcentred primary care.

Funding for preparedness is difficult to establish and maintain; political systems across countries of all income levels focus on immediate and visible problems rather than prevention of future harms, particularly harms that are hypothetical and may not occur until after the next election cycle. Similarly, in most countries, primary care systems do not have the political support needed to establish the funding and support they need to provide essential care, identify emerging health problems and rapidly detect, treat and prevent the spread of disease through vaccination or other means.

Each country as well as the overall global health architecture needs effective mechanisms to ensure that resources are invested; that actionable public health information is shared transparently and with verification mechanisms; and that robust mutual accountability mechanisms incentivise countries to report on progress made with invested funds, learn from mistakes and successes and build confidence in our common drive to increase readiness.

\section{TECHNICAL SKILLS}

In all public health efforts, it takes trained staff to transform financial resources into functional capacities. Practical, mentored training of public health experts needs to be scaled up and sustained. ${ }^{6}$ Field epidemiology training programmes need to be massively larger while further improving quality, so that graduates are on par with top epidemiologic experts anywhere in the world. ${ }^{7}$ In most countries, the public health workforce needs to be much larger, better trained, better able to design, implement, analyse and evaluate health risks and public health programs and better supported by public health agencies, healthcare providers and systems and the entire government. Other methods to increase technical skills, including distance learning, short-term training, collaboration among national public health institutes, a highquality technical network for readiness coordinated by WHO, regional collaboration and south-south learning, will all be essential. But training and technical support will only succeed if the first component-stable funding for the long-term employment with adequate salaries of public health experts, laboratory staff, and primary care providers-is in place.

\section{OPERATIONAL EXCELLENCE}

Asked after the eradication of smallpox what would be needed next for global health, Dr Bill Foege replied, 'The eradication of bad management'. Managerial capacity must be strengthened for planning, budgeting, evaluating and reporting. Stronger organisations, including national public health institutes, ${ }^{8}$ and bettertrained staff are needed, as are greater efficiency and transparency in managing public funds. Excellence in the execution of public health programmes requires functional organisations and effective systems for human resource management and accountability, procurement, contracting, communication and more. Without this, we risk an endless cycle of evaluation and failure instead of using the momentum of today to establish substantial and sustained improvements.

\section{CONCLUSION}

What is needed-improved governance, more money, greater technical skill and operational excellence-is clear. COVID-19 demonstrated that even robust public health institutions are not immune from inappropriate political interference. ${ }^{9} \mathrm{WHO}$ is the essential anchor of our global health architecture and must be reinforced by human resource policy improvements, increased resources, and functional partnerships with development banks and other organisations. Yet the scope of financial, technical and operational support required to respond effectively to the next pandemic is likely to remain beyond the reach of any single institution. Further improvements in WHO are necessary but not sufficient to greatly improve global readiness.

Creation of a new entity to oversee preparedness and response would likely be controversial, take years, and dissipate momentum generated by the COVID-19 pandemic as well as create distractions that could squander the world's greatest opportunity in a century to greatly improve the ability of public health systems around the world to better protect against health threats. An existing institution or institutions (eg, the Global Fund) may be an effective home to channel financing for global, regional and national preparedness initiatives.

Adjacent areas might be parts of a new global health architecture. Laboratory errors are inevitable, and there are insufficient global standards-and no global oversight-to reduce the risk of unintentional release of deadly pathogens, as likely already occurred with influenza $^{10}$ and is documented to have occurred with SARS ${ }^{11}$ and smallpox. ${ }^{12}$ Biological releases can be as deadly as nuclear war, and a similarly robust system of standards and inspections could reduce, although not eliminate, global risk. COVID-19 has demonstrated convincingly that economic stability, education, agriculture, security, social services and other social and economic support are integral parts of an epidemic response. The UN is the logical place for such coordination to occur, but WHO and UN success will require the commitment of member 
states and collaboration with the private sector and foundations. The UN has a unique ability to encourage communication, cooperation and commitment.

COVID-19 has revealed the inadequacy of public health capacity in many countries as well as of the current global health architecture. Substantial increases in funding for preparedness and in funding and efficacy of WHO are urgently needed, but these two measures will not be sufficient for the global health protection the world needs. Substantial commitment of financial and political capital at the country level, combined with robust, practical, sustained technical assistance to strengthen country capacity, solidarity to provide mutual assistance, and rigorous accountability through external verification with incentives for cooperation will also be necessary for success. One approach to increasing accountability would be to determine and publish whether every suspected outbreak is identified within 7 days of emergence, reported within 1 day with investigation begun then, and control measures in place within 7 days-a "7-1-7" target. ${ }^{13}$ Funding could flow through existing entities, such as the Global Fund and development banks.

In sum, the world needs four inter-related and substantial changes: substantial new funding; improved country and global governance, robust technical support, and rigorous accountability. Success will require at least US \$5-10 billion a year of new funding for at least a decade, with efficient financial mechanisms, stronger commitment to collaboration and new ways of working together that recognise the reality-so vividly illustrated by the COVID-19 pandemic - of our mutual dependency and mutual accountability. We may never be able to be as prepared as we need to be, but we cannot afford to continue being as unprepared as we have been.

Twitter Thomas R Frieden @DrTomFrieden

Acknowledgements The authors thank Dr. John-Arne Røttingen for helpful input on an earlier draft of the manuscript, and Drew Blakeman for assistance with manuscript preparation.

Contributors All authors made substantial contributions to the conception or design of this work, drafting and critical revision for important intellectual content, give final approval of the version to be published, and agree to be accountable for all aspects of the work in ensuring that questions related to the accuracy or integrity of any part of the work are appropriately investigated and resolved.

Funding Resolve to Save Lives, an Initiative of Vital Strategies, is funded by Bloomberg Philanthropies, the Bill \& Melinda Gates Foundation, and Gates Philanthropy Partners, which is funded with support from the Chan Zuckerberg Foundation.
Competing interests Resolve to Save Lives, an Initiative of Vital Strategies, is funded by Bloomberg Philanthropies, the Bill \& Melinda Gates Foundation, and Gates Philanthropy Partners, which is funded with support from the Chan Zuckerberg Foundation.

Patient consent for publication Not required.

Provenance and peer review Not commissioned; internally peer reviewed.

Data availability statement All relevant data are included in the article.

Open access This is an open access article distributed in accordance with the Creative Commons Attribution Non Commercial (CC BY-NC 4.0) license, which permits others to distribute, remix, adapt, build upon this work non-commercially, and license their derivative works on different terms, provided the original work is properly cited, appropriate credit is given, any changes made indicated, and the use is non-commercial. See: http://creativecommons.org/licenses/by-nc/4.0/.

ORCID iD

Thomas R Frieden http://orcid.org/0000-0002-4759-2256

\section{REFERENCES}

1 International Monetary Fund. Global prospects and policies. In: world economic outlook: a long and difficult ascent, 2020. Available: https://www.imf.org/en/Publications/WEO/lssues/2020/09/30/worldeconomic-outlook-october-2020 [Accessed 27 Jan 2021].

2 Patrick S. When the system fails: COVID-19 and the costs of global dysfunction. Foreign Affairs, 2020. Available: https://www. foreignaffairs.com/articles/world/2020-06-09/when-system-fails [Accessed 27 Jan 2021].

3 Craven M, Sabow A, Van der Veken L. Not the last pandemic: Investing now to reimagine public-health systems. McKinsey \& Company, 2020. Available: https://www.mckinsey.com/industries/ public-and-social-sector/our-insights/not-the-last-pandemicinvesting-now-to-reimagine-public-health-systems [Accessed 27 Jan 2021].

4 World Health Organization. A world in disorder: global preparedness monitoring board annual report, 2020. Available: https://apps.who. int/gpmb/assets/annual_report/GPMB_AR_2020_EN.pdf [Accessed 27 Jan 2021].

5 Redd SC, Frieden TR. CDC's evolving approach to emergency response. Health Secur 2017;15:41-52.

6 Davis FG. Mentoring in epidemiology and public health training. Ann Epidemiol 2013;23:524-7.

7 Williams SG, Fontaine RE, Turcios Ruiz RM, et al. One field epidemiologist per 200,000 population: lessons learned from implementing a global public health workforce target. Health Secur 2020;18:S113-118.

8 Frieden TR, Koplan JP. Stronger national public health Institutes for global health. Lancet 2010;376:1721-2.

9 Gonsalves G, Yamey G. Political interference in public health science during covid-19. BMJ 2020;371:m3878.

10 Rozo M, Gronvall GK. The reemergent 1977 H1N1 strain and the gain-of-function debate. mBio 2015;6:e01013-5.

11 Normile D. Infectious diseases. Mounting lab accidents raise SARS fears. Science 2004;304:659-61.

12 Hawkes N. Smallpox death in Britain challenges presumption of laboratory safety. Science 1979;203:855-6.

13 Frieden T. Will we be ready for the next pandemic? 2021The Wall Street Journal. Available: https://www.wsj.com/articles/will-we-beready-for-the-next-pandemic-11613145677 [Accessed Mar 8, 2021]. 